\title{
Annals of the American Association Routledge of Geographers
}

The 'Smart Safe City': Gendered time, speed and violence in India's urban age.

\begin{tabular}{|r|l|}
\hline Journal: & Annals of the American Association of Geographers \\
\hline Manuscript ID & AN-2018-1045.R2 \\
\hline Manuscript Type: & Revised Manuscript \\
\hline Manuscript Category: & Human Geography \\
\hline Key Words: & Smart City, Gendered time, Urban peripheries, Slow violence, Margins \\
\hline
\end{tabular}

\section{SCHOLARONE \\ Manuscripts}


Table 1: Violence seen from the top down Smart Safe City vs. life in the margins

\begin{tabular}{|l|l|l|}
\hline Violence & Smart safe city & Life in the margins \\
\hline Timeframe & Fixed, instantaneous & daily, generational, lifetime \\
\hline Pattern & Aggregated & Uncertain, sporadic, cyclical \\
\hline Past time & Regulated, coded & Social and gendered time \\
\hline Future action & Projected, efficiency & Reflection, internalisation \\
\hline Slowness & Download, crashing, not real time & Police, judiciary, family norms \\
\hline Technology & Smartphones & Broken, disconnected or absent \\
& & Infrastructures \\
\hline
\end{tabular}




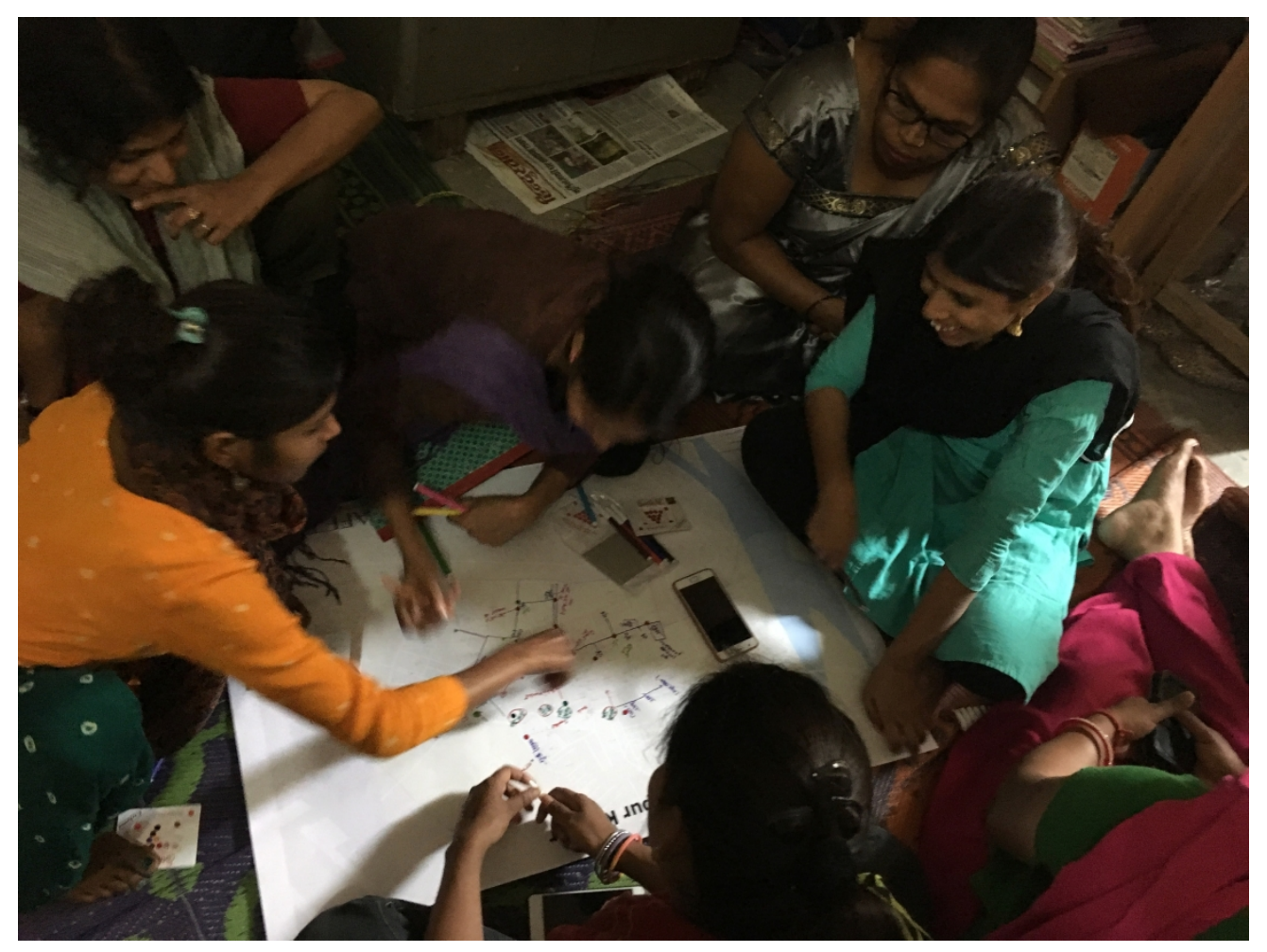

Figure 1: Time mapping during a participatory workshop. Photo: Author. 


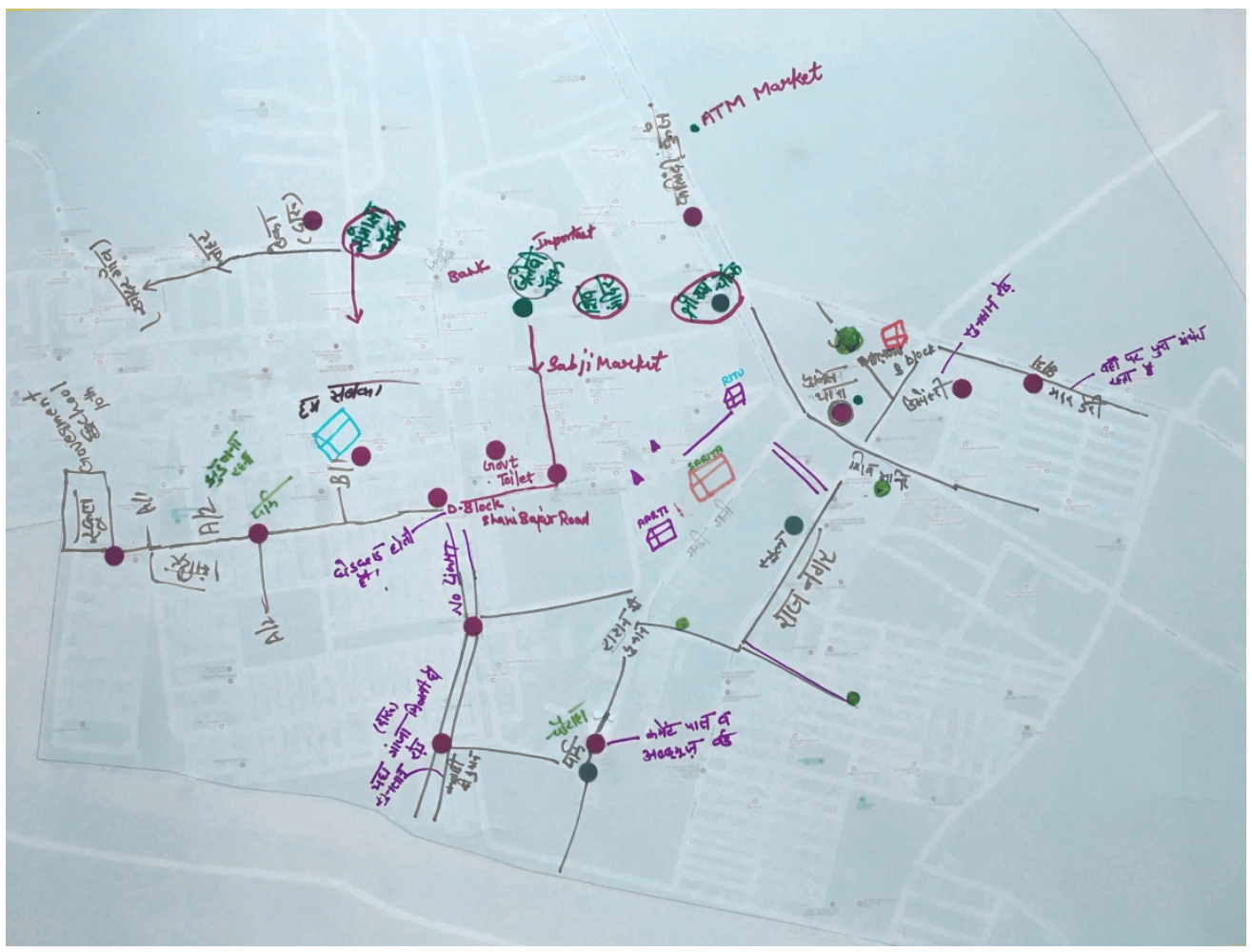

Figure 2: Participatory time-mapping. The red dots and lines represent spots and routes respectively, where they are sexually harassed or catcalled.

$1441 \times 1091 \mathrm{~mm}(72 \times 72 \mathrm{DPI})$ 


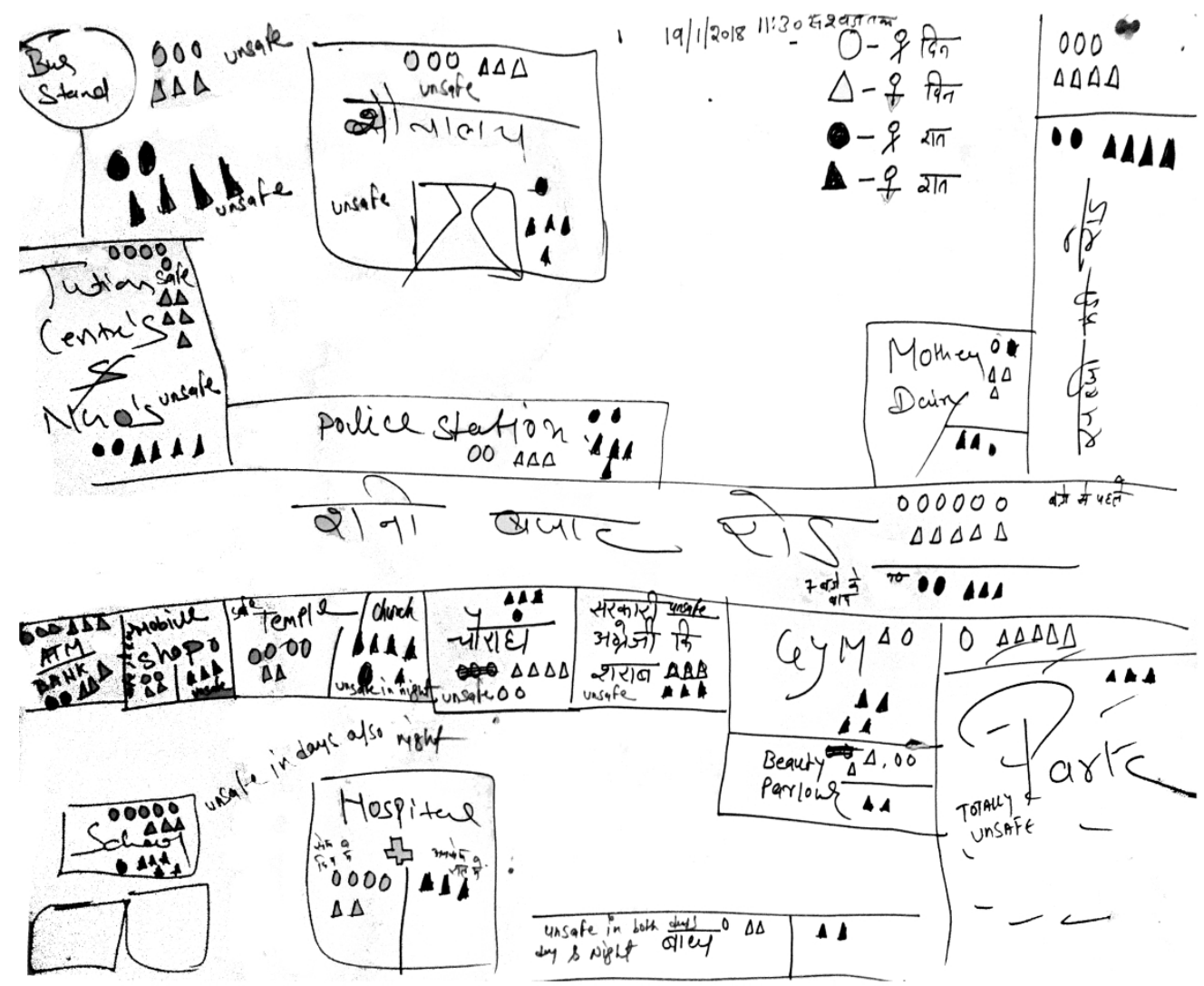

Figure 3: Time-mapping conducted with women participants. Source: Jagori 


\title{
The 'Smart Safe City':
}

\section{Gendered time, speed and violence in the margins of India's urban}

\author{
age. \\ Ayona Datta \\ Professor of Urban Futures \\ Department of Geography \\ University College London \\ 26 Bedford Way \\ London WC1H 0AP \\ Email: a.datta@ucl.ac.uk
}

Abstract: Speed is fundamental to shaping visions of the modern city and of contemporary urban life. Notions of speed and acceleration have produced distinct conceptualisations of rapid urbanization as a rush towards progress and opportunity. In this paper, I examine what speed looks like from the margins, when seen through the struggles of young women in the urban peripheries who are coping with the precarity of working in the city, while negotiating deeply entrenched gender power relations within the home. By examining how speed is conceptualised through the trope of the 'smart safe city' and what this means for those living in the digital and urban margins, I examine how a negotiation of time becomes fundamental to gendered life in the urban periphery. Using methods of timemapping, participatory workshops, whatsapp diaries and in-depth interviews, I will argue that for those in the margins, everyday life is entrenched in time struggles between the rhythms of the city and the rhythms of family life. While the focus on the 'smart safe city' in India 
mobilises the logics of a 'technological fix', for young women, the mobile phone is a significant technology to cope with daily time struggles. This paper will conclude that while transformations of ideas of speed and time in the smart safe city shapes practices of measuring, visualising and representing violence against women through technology, those in the urban peripheries encounter and negotiate its spatio-temporalities through a slow violence of life that is invisible and unfolding over time and space.

Keywords: Safe City, Smart City, Urban peripheries, Gendered time, margins, speed, slow violence. 


\section{The Smart Safe City}

'The goal of Delhi Safe City program is to build a safe and inclusive city where women and girls are enabled to live a life free from sexual violence, and from the fear and anticipation of such violence. Women and girls have a "right to the city". The overall objective is to strive to eliminate violence against women and girls.' (Govt of NCT of Delhi 2014).

In 2013, just after the very publicised Nirbhaya sexual assault case, the Delhi government joined the UN Safe Cities programme in partnership with a number of NGOs and feminist organisations in India. The Delhi Dept of Women and Child Development commissioned and co-wrote several reports on the state of safety via surveys, focus group consultations and 'safety audits' and made recommendations on several aspects of gendered safety in public places of the city (Jagori n.d.) Seeing safety as a gendered right to the city, the Delhi Government recommendations outlined several aspects of safety that could be enhanced in terms of infrastructure, governance, security arrangements and design of public places. Concurrent with these developments, the Delhi Police launched a new free app called 'Himmat' to increase response rates to crime, particularly Violence Against Women (VAW).

At the same time a national 100 smart cities mission also included several guidelines on safety within the requirements of creating Smart City (SC), in particular suggesting that the SC "has high levels of public safety, especially focused on women, children and the elderly; men and women of all ages feel safe on the streets at all hours. (Guideline 6.2)". Soon after in 2015, Delhi's Home Minister announced that its smart city policies would align with and target the UN Safe city recommendations. The Delhi proposals were: to make the central business district 'Dark Spot Free', install 310 CCTV surveillance cameras in all major markets and 700 CCTV surveillance cameras in 72 residential colonies, and improve pedestrian safety. This approach was directed towards the ubiquitous connectivity offered by 
smart city packages to address public safety for women as a time-bound event in the city measured by incident and response rates and its visualisation in command and control centres. Yet in 2018, Himmat had only 30k users out of 19 million population in Delhi, and was declared a 'failure' by a Parliamentary Panel (Indian Express 2018).

The coming together of the smart city (ie digital infrastructure) and safe city (ie. Addressing VAW) logics into a hybrid 'smart safe city' upholds what Thomas (2018) has labelled as 'Government 2.0' - a new type of governance transformed by the use of ICT to tackle deep seated urban and cultural/societal concerns. This government is a digitally enhanced version of the earlier 'Government 1.0' which was geared towards transforming governance via partnerships with the private sector. The smart safe city as a new logic of gendered fear of violence is the city transformed and remade through the perceived temporality of crime and violence against women. In asking citizens to download safety apps and use them for their safety, the smart safe city also promotes a 'consumption of security' (Virilio 2006, 139) through the production of a 'new composite portrait of the citizen - no longer the one who enriches the nation while consuming, but the one who invests first and foremost in security, manages his own protection as best he [sic] can and finally pays more to consume less'.

As a programme within Delhi's wider smart city initiatives, Delhi's safe city proposals can be seen as a new 'ICT mediated social order' (Gurumurthy and Chami 2014) that uses a preventative 'right to the city' approach in dealing with the spatial and temporal nature of VAW. In the Himmat app, time is experienced as moments when women's bodies are made to 'willingly position themselves within, and actively contribute to, an urban security calculus as a means of minimizing their own personal exposure to urban risks presented by risky bodies in risky spaces.' (Leszczynski 2016). Incorporating Himmat as part of the smart safe city presents a 'future popular self-governance of civil fear' (Virilio 2006, 138). It brings 
together two parallel and seemingly unlikely discourses to find a technological fix to the governance of safety in the smart city. The smart city as a ubiquitously connected urban space has its primary goal directed towards effective and efficient governance of VAW. The safe city monitors women as the 'victims' of crime who are part of the algorithms of ubiquitous surveillance offered by smart city packages. This claims to offer two 'benefits' the speed of rapid and connected response to crime, and the crowdsourcing of knowledge and information on incidents of VAW through the use of smart safety apps. Taken together, the logics of both smart and safe city works by counting, measuring and connecting the spatiotemporalities of instantaneous violence pinned on a map.

This approach shows how a logics of speed vested in the increasing 'techno-digitization of cities' (Herzog 1995) imagines violence against women as a set of asynchronous urban events, rather than cyclical, periodic and socially significant time-spaces of gender power inequalities. In this, the everyday as a repetitive process full of temporal pressures, constraints and freedoms are compressed into the geo-located data point of violence in the map. Here as Virilio $(2006,157)$ notes, speed is the 'destiny, a form of progress' towards resolving violence, moving the body from its corporeal socio-historical temporality to an event on the map. Instantaneous time as a measure of violence becomes fraught with the colonisation of women's bodies, which co-opts those that it seeks to 'liberate' within the rhythms of the app.

Unlike the instantaneity of VAW in the smart safe city, time and speed look very different for women living life in the margins. Daily struggles with water and energy shortages, lack of public toilets and unreliable public transport, make speed itself a utopian aspiration. Rather than the perceived efficiency of smart technology, women in our research had a social and cultural understanding of violence that could not be measured in instantaneous time. Instead, the imposition of speed was experienced as 'slow violence' 
(Nixon 2011) - 'a violence that occurs gradually and out of sight, a violence of delayed destruction that is dispersed across time and space, an attritional violence that is typically not viewed as violence at all.' This violence in the margins of the city was spatio-temporal, experienced as generational, historical, cyclical and corporeal - produced from social, cultural, infrastructural and technological constraints over the movement of their bodies in space and time.

In this paper, I will examine speed, time and violence through a spatial economy of gendered social time in the urban peripheries. I will argue that this slow violence since it is driven by the imperative and aspirational technologies of speed mobilised through technology and stalled through distance (social, physical and symbolic). In broad terms, I examine what speed looks like from the margins of the city, when seen from the vantage point of young women struggling to find jobs and gain education in the city, while negotiating deeply entrenched gender power relations within the home. By examining how speed is conceptualized in the trope of the smart safe city and what this means for those living in the urban peripheries, I examine how a negotiation of time becomes fundamental to living life in the margins.

\section{Speed, violence and the urban margins}

Speed has been fundamental in shaping the modern city. Notions of speed (in its calculability, connectivity and acceleration) produced distinct conceptualisations of 'spacetime compression' in global processes of capitalism, neoliberalism and urbanization since the $20^{\text {th }}$ century. In the urban age, speed is shaping new vocabularies of the future (such as fast forwarding, future proofing, leapfrogging, fast tracking), new forms of urbanism (in smart cities) and new domains of state rule (streamlining bureaucratic and regulatory processes, efficiency measures, e-governance, Big Data). This story of speed is being told through a 
visual imagery of urbanisation that is represented both as the real-timeness of applications as well as the future time of accelerated urbanism.

What does speed look like from the urban margins? Scholars (Herzog 2014) tend to put speed as a feature of fast urbanism and therefore in opposition to a parochial notion of slow time constructed by the urban poor. Urban time, Herzog argues, presents us with an asynchronicity between the speed of digital and networked city and the slowness of everyday life at the margins. Writing about speed and politics in the context of modern warfare, Virilio (2006, back cover) noted that speed is 'not the annihilation of space-time but the 'wide phenomenon of technological contraction.'. Kitchin too notes that the timescapes of smart cities 'necessitates seeking to harmonize and synchronize the temporal rhythms of a diverse set of practices and processes' (Kitchin 2019) shifting towards more efficient and streamlined response and action. The social, economic and political implications of speed are now increasingly evident through 'fast urbanism' (Datta 2017) - a management of speed of urbanisation in the peripheries that are growing at a faster pace than the metropolitan cores. Fast urbanism supports the idea that urban peripheries are spatio-temporalities par excellence because of the waves of unmaking and remaking of its territories, built environments and populations. It means that while speed becomes the fundamental transforming power in the peripheries, it also becomes a utopian imaginary for both the state and marginal citizen alike.

Whilst there is much critique on the different approaches of smart safe technologies (Adur and Jha 2018; Elwood and Leszczynski 2018; Gurumurthy, Chami, and Thomas 2016; Keller, Mendes, and Ringrose 2018; Light 1995), this body of work has been largely silent on the speed vested in instantaneity and ubiquitous connectivity. Further, there is little that we know of the gendered, classed and geographic unevenness of time and its territorialisation in the margins, and thereby its relation to structural and gendered violence. There is thus still a need for more in-depth, comprehensive, visual and textual analysis of how visions of speed 
ontologically frame the rhythms of gendered violence, and what this means for those living outside the grid of the smart safe city. Such an analysis is important because a) speed is still used to create binaries between the modernist city and its parochial margins. The pace and rhythm of the mega-city is often constructed through particular vocabularies of speed in opposition to the 'pre-modern futures' of the peripheries characterised by broken infrastructures, poor connectivity and inept institutions of governance. b) digital technology is producing a whole new image of the future city through smart safety apps which has rendered the peripheries with splintered infrastructures (Graham and Marvin 2001) The significance given in contemporary city visions to strategies of fast urbanism has paradoxically framed metropolitan cities as the synecdoche of speed, although we know that the speed of urbanization is mainly evident in the transformation of the urban peripheries. c) Despite a deep commitment to studying cities as key sites of globalisation, neoliberalisation and capital accumulation, speed still remains undertheorized in feminist and urban geography. An approach that is only emerging is the focus on speed by the smart safe city as a 'strategy of accumulation' where cities are increasingly used as 'growth machines' (Chien and Woodworth 2018). Indeed struggles with speed in the margins can create new exclusionary 'timescapes of daily life that continues to perpetuate inequalities between communities.'(Kitchin 2019). In particular there is little understanding of how the politics of gendered time shapes notions of speed in the margins.

\section{Postcolonial futures, feminist time and 'slow violence'}

In postcolonial contexts, time has been central to the conceptualization of the binary between tradition and modernity (Chakrabarty 2000) - the former seen as slow and the latter as the speeding up towards a technological future. Colonial subjects viewed or understood their social world through the values associated with Western clock time, commoditised and rationalised spatio-temporalities imposed as norms on their spaces and territories to rule and 
discipline. As recent studies of the future have confirmed (Adam 2008; Amin 2013;

Anderson 2010; Sardar 1993) - the control of time is a route to gaining and reinforcing power over populations and territories. Milovejic' argues that 'Social groups able to impose their own approach to time to others, through normalisation and universalisation of 'hegemonic' time also succeed in 'controlling' both the present and the future in indirect ways'. Indeed control over gendered time means the power to manipulate subjective identities of childhood, youth, single life, motherhood, parenthood, worker, community and fit them within the existing linear times of progress, modernity and development. Time as power then facilitates fundamental shifts in the 'time-space-being-movement/change axis' (Milojevic' 2008) of subjects and citizens.

In the postcolonial moment, gendered power is evident simultaneously in the 'colonization with time' and 'colonization of time' (Adam 2004). This colonization extends to the times and spaces of subjecthood, being and belonging in the future. A gendered colonization of time is the time of policy that is evident in the empowerment and development initiatives that have time-bound outputs and expectations from national and urban governments. This was evident in the early 90 s with the imperatives of UN Smart Economics policies that sought to empower women by bringing them into the workforce as an economic common sense. In this framing women's time was colonised through policy timelines and indicators, GDP growth and measurements of age and growth of female workforce. As Chant (Chant 2013) argues, this was a 'far cry from the nuanced and subjectsensitive ideas of what the empowerment of women and the attainment of gender equality actually entails, to be found within the gender and development literature'. The colonisation of gendered time - daily routines, the rhythms of the family, cycles of work, education, and social reproduction is evident is more recent $\mathrm{UN}$ policies of SDG\#5 and \#11. They further colonise gendered time through the continued support of ICT as an indicator of "poverty 
reduction and development agenda; and its role as a key 'enabler' of human rights'(Gurumurthy and Chami 2014). These time-bound policy measures and indicators are present in the Millennium Development Goals (MDG), the Sustainable Development Goals (SDG) as well as in reports of UN Special Rapporteurs, OECD, G8 and the European Council. This colonization of time reappears in the smart safety apps. Colonisation of time is also evident in the speed and pace of urbanization that is fundamentally altering the grain of urban governance. Time-based approaches to governing the city shift from socio-spatiality to a spatio-temporality of the postcolonial subject evident in India's smart city projects, produce particular types of citizens as economically valuable entrepreneurial and self-regulating citizens, therefore as worthy of belonging in the future city (Datta 2018).

A gendered colonization with time can be seen in the participation of postcolonial subjects in producing time as an exchange value through time management, time economies, surplus time, time pass and time poverty. This brings with it new complexities 'around social time, new expectations of speed and violence of gendered spaces' (Adam 2004, 120). Although subjects uphold the colonization with time in their daily routines, their organisation of everyday lives along different temporal trajectories suggests a degree of alterity with Western clock time. For example, while women might be able to access urban services and livelihoods through advances in technology, they nevertheless struggle with the socio-cultural constraints imposed by the power of clock time in travel timetables, family routines, water supply hours, toilet opening hours and mobile network access times. Speed produces new subjects compliant with the spatio-temporalities of urban transformations (such as participatory governance, public infrastructure use, mobile payment systems, biometrics, digitisation etc) but they also transform the practices of citizenship to align with gender and class struggles from the margins. Indeed Jeffrey (2010) has observed how 'timepass' is a key strategy of negotiating the future for unemployed urban youth, especially when promised 
access to political freedoms, social goods, or economic resources is delayed. Datta's (2012) work has shown that for the urban poor living in slums, 'waiting for demolition' offers the time-spaces for critical learning and consciousness, that produce new rights claims to the future city. In his examination of development futures in Mumbai slums, Appadurai (2013) also notes how 'patience' becomes a resource for the slum women as they campaign for toilet rights from the state.

These forms of colonization of/with time can be seen as 'Slow violence' (Nixon 2011) - a multi-layered, infrastructural, social and spatial process of unfolding and accumulative injuries that are both historical and gendered. This is a violence that Nixon argues 'is neither spectacular nor instantaneous, but rather calamitous and accretive, its calamitous repercussions playing out across a range of temporal scales'. Although we know very little about its features in the urban peripheries, the heterogeneous and unorthodox nature of slow violence is shaped by the struggles to respond to and negotiate the imperatives of speed wrought from above - incessant urban development, large-scale slum evictions, ever shifting employment sectors, demands on efficient labour and so on. Slow violence occurs in a context where the impacts of delays in water supply and increasing power cuts, loss of home to urban development, evictions from the city and relocation to the urban edges, increasing travel times, are accrued over generations and across families to produce long-term gendered inequalities that are invisible compared to ways that the spectacular nature of VAW are measured, mapped and visualised in the smart safe city. Women in the peripheries struggle for, against and with speed and time in everyday life by producing new imaginations of urban futures from below. These struggles are tied to the recognition of vernacular, non-linear and cyclical nature of everyday work, travel and family time.

Much of the scholarship in urban studies is a 'static study of the present' (Bell and Mau 1971, xiii), with little focus on how anticipatory actions of speed, time and fast urbanism 
demand the management of urban life. Understanding how speed and time shapes slow violence therefore remains a 'wicked problem' (Tutton 2017) of feminist and urban geography alike because it 'derives largely from the unequal attention given to spectacular and unspectacular time' (p6). Unlike the spectacular and instantaneous time of VAW, slow violence reflects the 'attritional catastrophes' of structural violence that remain unspectacular and normalised. Using the lens of slow violence, we will examine urban peripheries in their own terms by forging a theoretical and conceptual apparatus that is adequate to the understanding of the 'delayed effects' (Nixon 2011) of devastating inequalities in allocation of time across space and its 'consequential forgettings' by those who are colonised by it. This will mean unpacking what speed is in the everyday lives of the urban poor, how it shapes their understanding of the social, political and material impacts of urban marginality, and the potentialities for creating feminist urban futures. From a postcolonial perspective, this means approaching the politics of the poor as a politics of speed-time. It means recognising that the city is made through the struggles of urban poor women around time-poverty and time-struggles. These are tied to struggles for the recognition of vernacular and cyclical nature of time rooted in work, travel and family life of these women. These interdisciplinary approaches from urban and postcolonial studies, sociologies of time and future studies open up new and ground-breaking theoretical and empirical stances to understand how speed is fundamental to the transformation of gendered life and violence in the urban margins.

\section{Time mapping method}

The paper is written from a Research Council funded comparative project that seeks to curate women's experience of gender-based violence in low-income neighbourhoods in Delhi's and Bangalore's peripheries. The wider project aim is to understand how top-down imaginaries of the smart safe city could be understood through the digital lives of women living in the urban margins. The expected outcome is a series of co-produced and curated 
installations with the women which would engender the smart safe city from the margins. Both the cities provide a comparative angle given both have repeatedly been highlighted in the national news for violence against women, while also offering one of the most digitally enhanced lives for its citizens in India. The strategy of co-production was in line with the wider aim of the project to build capacity amongst the women to tell their own experiences of urban marginality and violence through digital and mobile technology. How these digital lives in the city could be curated via mobile technology formed a crucial element of the research.

The network included partnerships with an NGO who had been working with feminist methods, running youth training camps and domestic violence counselling for almost two decades. The NGO had identified 'a core group of 35 girls and 25 boys in the 13-20 age group to be trained as activists' (Jagori n.d.). They saw a potential in their programmes to enhance the use of digital technologies and empower women to speak through technology as well as witness and curate violence through multimedia and alternative means of communications. We also formed a partnership with an ICT social enterprise which had developed an app to collect data on infrastructure and social use of space, as a way to inform gender sensitive planning and governance. The app was also used to collect information about the use of spaces via safety walks with the women, that then could be represented and geo-located on a map. This data was translated into safety scores that could be represented on a map of the city. Using this app, the ICT enterprise had already collected data of over 4000 $\mathrm{km}$ of roads across Delhi, which resulted in around 50,000 audit points in Delhi, which included the neighbourhood under study.

In the first phase, we focussed on two resettlement projects in Delhi's urban peripheries, where the NGO partner had a presence. We conducted semi-structured interviews and mental mapping with over 30 women. The safety audit data was made 
available to us by the ICT enterprise to discuss with the women during interviews. After a period of analysis, we conducted a time-mapping workshop with these women (Figure 1), through which we recruited 11 women to participate in an extended period of curating their daily experience of navigating the city via WhatsApp. A representative from our NGO partner set up a closed WhatsApp group where the women were requested to upload their diaries on a regular basis. This resulted in a rich multimedia sharing of experiences of moving around the city through text (in English and Hindi), videos and voice recordings.

Figure 1: Time mapping during a participatory workshop. Photo: Author.

The participants were women who were young urban citizens. They had mostly attended youth training programmes offered by our partner NGO working in the colony, many of whom had participated in the Safety walks run by the ICT enterprise. They had either grown up in the colony or were evicted there with their families when they were very young. As a result they saw themselves as 'urban' citizens with little connection to rural origins or slums. They therefore tried to live in the colony on their own terms, negotiating with their parents continuously to relax the times of curfews over their bodies and mobility. Of the women, two were divorced, one was a single mother, and they were all precariously employed - in poorly paid service or NGO jobs. There were strong restrictions on their mobility, although they were still some of the most mobile women in their colony as a result of their involvement in the NGO activities which took them to different parts of Delhi or India. Indeed, one of the women had to leave this project mid-way because her mother did not wish her to continue with the next phase of the project.

None of these women had access to desktops or laptops, and they did not have the time to visit internet cafes. Their experience of the digital age was through the interface of the mobile phone. They used their mobile to download news and videos on YouTube or 
WhatsApp and were thus largely reliant on forwarded messages. Use of IE browsers or Google Chrome was not very common, which was a challenge when they had to find jobs or access government schemes or educational opportunities. Their limited English language skills also meant that browser searches such as these were time-consuming and laboured processes.

The multimedia content from the WhatsApp diaries, the mental maps and the interview narratives suggest that time was a key constraint that women struggled with on a daily/hourly basis. This was acutely felt during regular debriefing meetings with our research assistant on Sunday evenings. Most of the women were engaged in evening college or adult education classes, or in employment. They would invariably be late because of delays in public transport, or be unable to come because the timings clashed with their work schedules or classes. The experience of violence as well was synchronous with the routineness of their daily mobility - fleeting glances on the road, broken walkways, interminable waits for public transport and the momentary panic in a bus filled with men. The time-space of violence was corporeal, performative and lived but despite our co-presence in the WhatsApp group, it was challenging to get them to update their diaries regularly. This itself was a very strong indicator of their time poverty, since it was evident that they were all very enthusiastic about the project, but struggled to participate. Updating also implied that they had recognised what was worthy of reporting - which was the hardest part since so much of the violence they experienced regularly had been normalised as mundane. The findings below are therefore produced from these restrictions of time, space and digital and language capacities.

\section{Delhi's 'networked margins'}

Recent scholarship on India's urbanization has noted that its 'urban age' is located primarily in its urban peripheries which are undergoing rapid transformations (Banerjee-Guha 2010). An emerging scholarship focussing on urban peripheries have noted the largely 
exclusionary impacts of development on its marginalised communities - Dalits, Muslims, migrants, and women (Tacoli and Satterthwaite 2013). Yet while the focus of research in urban peripheries have tended to draw our attention to the absence of infrastructure - water, sanitation, electricity, domestic energy and so on, there is little acknowledgement of the digital as another form of infrastructure that is deeply unequal and is exclusionary for women living in urban peripheries. This is not least because as Sarkar notes, 'there is little ethnographic and critical work on ICTD initiatives in deeply unequal, urban contexts in India.' (Sarkar 2016), but also because digital and mobile technologies remain largely absent in the conceptualisation of 'urban' transformations.

Since India's liberalisation in the 1990s, there has been a 'silent revolution' (Hoelscher $2016,32)$ in the ICT and telecoms sector, yet, aspirations for an urban age through widespread application of Information and Communications Technologies (ICT) and digital infrastructure in existing cities, have been largely unmet outside metropolitan cores. The urban margins have been largely confined to the take up of mobile-based technology both in communications as well as internet, becoming the 'networked margins' (Shah 2015, 9) simultaneously networked digitally (through access to mobile phones) while substantially disconnected from the grid of urban infrastructures. Slow violence in this context is the accrued violence of gendered exclusions across digital and physical spatio-temporalities, which is invisible and as yet unmapped. At the same time, the speed with which women in the urban peripheries can access education, work and services compared to their previous generations makes them part of 'a growing tribe of digital natives in India, who are deeply embedded in the digital market not merely as customers, but also as users and shapers of technology.' (Thomas 2018,6) Their use of the mobile phone helps them to live their life between speed and slowness, in keeping with the increasing speed of connectivity demanded of young women in search of jobs, education and information, but also at the same time the 
slowness in dropped connections/calls, absent urban infrastructure and control over their mobilities by their families.

This paradoxical inequality is reinforced by the speed of transformation of Delhi's urban peripheries since the 1990s when waves of slum demolition programmes just before the Commonwealth Games in 2000 forcefully evicted squatters from different parts of the city to resettlement colonies along the metropolitan boundaries. Much has been written about the injustice of these evictions following a judicial order by the Supreme Court, and the struggles that early evictees faced when relocated to the peripheries where there was little access to basic infrastructure and transport connections with the city (Bhan and Menon-Sen 2008). The resettlement colony where they live can be placed along these lines of historic inequalities and exclusions from urban Delhi. Squatters resettled here in 2002 were awarded only 12 sqm of land for building their houses. Electricity was provided four years after resettlement, and public toilets are still inadequate in several areas of the colony (The Hindu 2004).

The women who were participants in this project were very young or not born at the time, and therefore have little memory of the early days of resettlement and struggles with accessing basic infrastructure. They recall stories told by their parents or older members of the family about the dangers and fears of being evicted to the urban peripheries with no water, sewage or lights, with dark unpaved roads and hostile villagers nearby whose fertile land had been acquired by the government and sold to the evictees at subsidized rates. These stories enabled them to compare how the slow unfolding of time in bringing them closer to urban infrastructure and its relations with violence itself had transformed two generations.

The slow transformations in the colony over two decades in the infrastructure of water, sanitation and electricity was largely possible through the initiative of the residents who had campaigned repeatedly and continued to drive change through regular petitions to the utility 
companies and to the municipality. This is in contrast to the speed of transformation in digital technologies and infrastructure which has provided the women with fantasies of speed in communications and connectivity. This dialectic between the old and new is experienced by the women through the proliferation of cheap android phones and smartphones bought in the second-hand market, which have positioned them as a new social class of digital natives in the urban peripheries. While physical infrastructure in the colony might be absent, broken or reflect the slow time of service delivery (water, sewage, sanitation, electricity and broadband fibre-optic cables), the speed of connectivity via mobile telephony offers access to information and knowledge without material improvements in urban basic services. At the same time, the promise of digital technologies also remains unfulfilled with slow speed of network coverage in the peripheries, dropped calls, older models of mobile phones which slow down app interfaces. These dialectics between speed and slowness across physical and digital infrastructures show how spatial asynchronicity is now an everyday feature of urban life in the margins for these women.

The women participants in our study were digital natives inhabiting the asynchronous spaces and times of violence between - infrastructure, connectivity and materiality. Like the case of the 'computer girls' (Sarkar 2016) of Seelampur, an urban resettlement colony in the margins of Delhi, the promise of inclusion in the information society and of crossing the digital divide, however never totally came to fruition for the women participants in this paper. Growth of Delhi's urban peripheries over the last two decades has meant increased transport connections via new metro and bus linkages, new local modes of transport such as the 'erickshaws' and thus increased freedom and mobility for these women; but this paradoxically also reinforced their vulnerability to violence. Women's role as wage earners outside the home as well as caretakers of infrastructure and services within low-income neighbourhoods is well documented (Datta 2012). Their simultaneous vulnerability to violence both inside 
and outside the home was also ironically a consequence of the perception of their moral corruption due to access to a wider compass of knowledge and information via the mobile phone. In their case, their freedoms were restricted by their time poverties around employment, education and familial duties imposed on their everyday lives. In this context, although feminist organising was a time burden on young women many of them continued to visit the NGO office in the colony and participate in several initiatives and training programmes.

\section{Mapping gendered time}

For women living in the urban margins and commuting to the city each day, their time was the space for struggles, and the centrality of time struggles in their life produced a perception of violence as spatio-temporal. This was what Adam has called 'women's time' the time of 'theory and practice, experience and explanation, lived orientation and material expression' (Adam 2004, 2). While the safety apps represent instantaneous time, the representation of our participants daily lives was all about the flows of time across safe and unsafe spaces. The participatory maps with women participants suggest an in-depth knowledge of the neighbourhood referencing not what is, but how they perceived, felt or imagined the time-spaces of violence.

Figure 2: Participatory time-mapping. The red dots and lines represent spots and routes respectively, where they are sexually harassed or catcalled.

Women did not speak of their time as clock time, rather as gendered time - the time which is full of constraints and struggles. Time in the participatory maps ( Figure 2) were cartographic and visual, that was represented with coloured ink as safe or unsafe. This was discussed as gendered time since these dangers were experienced and expressed as an aspect of their personal routes and routines through the neighbourhood. Temporality played an 
important role in this gendering, particularly when deciding when and where to step out of their homes, which routes to take to get in and out of their neighbourhood and where not to go at which times of the day.

Figure 3: Time-mapping conducted with women participants. Source: Jagori

Figure 3 shows how their neighbourhood was mapped as gendered time. The triangles standing for men and circles for women. Further the blackened symbols represented night time. The map suggests how most public spaces in the neighbourhood - gym, crossroads, Church, mobile phone shops, ATM and so on are male spaces in the evening. Indeed, the park was significant in that there were hardly any women there at any time of the day. The police station was even more significant in being a male space particularly at night, and therefore the police station itself were perceived as unsafe and threatening.

Like the safety apps, these time maps also present an algorithm of everyday life, but one that uses an intimate knowledge of time-space to express the anticipation of violence. While safety apps aggregate clock time and focus instead on its cartographic particularity, the time maps albeit cartographic, represent the cyclical pattern of violence across day and night. More significantly they also reflect how gender is seen largely as a binary category as male/female and by extension make perpetrator/female victim. On asking this question, participants noted that there were several men who they were friendly with - a phenomenon unthinkable in previous and current generations in their context, but was made possible through their association with the NGO youth camps. Participants claimed that although not all men they knew were perpetrators of violence, most men in their colony 'did not respect women'. Slow violence here were presented in the exacting curfew hours imposed by their families that overlapped with the absence of women on the streets after dark, which combined to make spaces occupied by men after dark feel unsafe. 
Speed, hoarding time and 'free' time

Adam notes that 'Rather than being elemental creatures attuned to natural rhythms, many women nowadays are, if anything, even more preoccupied with time measurement than men' (Adam 1995, 20). The women in our study too were if anything 'clock watchers ... who view time as a precious commodity to hoard or to spend' used to juggling between different timelines - family routines (particularly the imposition of curfew), work schedules, the challenges of public transport and bodily routines of hunger, sleep and exhaustion. Speed therefore was a normalised mode of urban aspiration, since without speed, one or more of their timelines would 'fail'. Those who struggled with the arrhythmic nature of these timelines would invariably either lose their jobs or face increased violence from families.

This was evident when our participants struggled to make it to our workshops on time or stay there for the duration of our sessions. Each of them had particular constraints of time, which led to delayed arrivals, early leaving and continuous phone calls to rearrange existing commitments in order to stay for the workshop duration. Particular to this was also the hoarding of time. I would hear participants saying on the phone 'I am leaving in 5 minutes' or 'I am on my way' while they continued participating in the workshop. This was an attempt to hoard time by stretching it so that an employer or a family member would not reach out for punitive measures when they were late. But participants also became frustrated with each other when they were hoarding time to contribute to our workshops, and yet others were not showing the same commitment. They would call out each other saying 'I know you did not leave work in good time to be here.' Or 'you think your time is more important? And I have been waiting here to start our workshops for the last 30 minutes'.

The mobile phone as a technology of time then provided them with a mechanisation of speed to coordinate these very different timelines - studying, working, cooking for family, attending NGO meetings and so on. The phone was an instrument of speed since it 
coordinated arrhythmic timelines into one rationalised system of measurement of clock time. Yet it was the ownership of this piece of technology that often presented the most challenging negotiations with family.

The first time I did a job, after my wedding, I told them, my family that I want to buy a phone. They said, what would you do with a mobile, why do you want a mobile? Who do you want to talk to? There is a mobile at home, if you want to talk to someone, you can use this. What would you do with a personal mobile?

Shah has argued that young people see 'the acquiring of the digital as a form of social and economic mobility and are catalyzed by its presence to bring about transformations in their lives' (Shah 2015, 10). Women participants noted that since their bodies and mobilities were often taken as proprietary property of their families, their need to personally own a mobile phone was seen as unnecessary or even threatening. Instead they were offered the use of basic mobile phones belonging to their mothers, or allowed to borrow the smartphones belonging to their father or brothers. This was particularly stressed when they stepped outside the home for 'legitimate' reasons such as work or education, since it enabled the family to keep in touch with them at all times. Indeed, for some of the women, their introduction to phone messaging through WhatsApp or Wechat was not through their personal accounts, rather through their mother or brother's accounts. Once they starting earning, the first item bought by these women was a mobile phone. This was seen as a gift of personal space, mobility and speed.

It is that with smart phones, a lot of earlier things which were difficult has now become easier, like crowds, like if you go to the bank, you have to stand in queues, or pay the mobile bill or electricity bill, or water bill, you can just put an app and pay it here at home itself, you don't have to go anywhere. 
Crucially, the phone enabled the women to smoothly navigate the city on their daily routes and routines as well as gathering more information about benefitting from different government schemes such as funds for economically weaker sections, funds for working women and so on. The mobile phone was thus an infrastructure of knowledge and information that enabled these women to increase their mobility and crucially enhance their geographical awareness about places in the city. It was often discussed as transformative in their lives.

Di, it is a very good thing, if we don't know something, sometimes they tell you, so here to this one's place in Badarpur, so how far is it from Khader, where to go - we can check all that, and even on whatsapp, there are groups and we can search and get help, it is very important to learn didi, there is so much in this.

While they often needed help from the research assistant for searching on google, navigating government websites, finding relevant information (not least because they were not strong in English language) they had far more in-depth understanding of using WhatsApp and social media to communicate with each other.

I don't know a word in English, for that [I use internet] Dictionary, and didi, what was that, we had done that [safety] audit, I had kept it, everyone in the group has it. If we don't know something or had to discuss something, then we use it [mobile]. Everyone has messenger, whatsapp and $\mathrm{FB}$, rest there are 1-2 apps, that was very informative ... And then there are groups, and there I learnt custard and rasmalai (a milk-based sweet) from YouTube.

Women's time was the time away from family rules and constraints around mobility, the time outside the limitations of their daily schedules and the time on their mobile phones, which enabled them to dwell in a parallel time of 'leisure' in ways that had not be possible earlier. Thus the phone not only overlapped the time of production and social reproduction, 
but also enabled them to access information in their 'free time'. Free time was not 'free' per se, rather the time in between two different timelines - between commuting and working, between family routines of cooking and childcare, between communicating with social networks and studying for college. Because the phone enabled instantaneous access to other times and spaces of information, it was suited to lives that were made from struggles with time-poverty.

Phone is an asset. But everything that has positive impact also has negative impact. So it depends on us and how we use it. Like whatsapp is good as well as bad too. We shouldn't make it a habit because you can connect easily with whatsapp and send audios, videos, like if we keep it working, we can send them. And we can use it if we face any trouble. But if we get addicted to it, then, that is a kind of harm too.

Thus the phone with all its freedoms was also about an ethics of time - "right action that contains accounts of what time is and what it should be used for.' (Bear 2016). The women had several stories of how men and boys used the phone to harass and stalk them. Thus, while the mobile phone was seen as an asset for enabling speed, it was also seen as a potentially immoral technology since it gave unlimited freedom in the hands of irresponsible users. This was when free time was converted into porn site viewing, stalking other women and making harassing phone calls. While earlier scholars have argued how items of technology such as the radio or tv have been seen in similar light, the introduction of the mobile phone as a bodily accessory to be carried on the go, enabling real-time harassment of others through various channels (social media, mobile chat etc) was seen as overlapping of free time with the time of technology .

Private and public time

Precisely because it provided universal freedoms and therefore the danger of violation, women felt they needed to be especially vigilant about protecting their privacy while using 
mobile phones. This was based on their experience of violence which first emerged in physical spaces of their neighbourhood or public transport but would 'bleed' into digital spaces through trolling, phone harassment and occasionally hacking. In dealing with this challenge, women separated their times and spaces as public and private. While the bus was a public space of transport, travelling in the bus was also private time - women would wear headphones, look down into their phones or pretend to be chatting in order to avoid being approached by men. Conversely, while their phones were private properties, women noted these as offering safer 'public' time by connecting with trusted friends and networks via social media, text messaging or WhatsApp. Indeed, some women also explained how they made others aware of this notion of private time embodied by the mobile phone, and the dangers of allowing strangers to enter this private space and time of their digital identity. Thus especially while being present in crowded places such as public transport, women were vigilant about online privacy making sure they did not reveal their phone numbers or social media identities to fellow passengers. This was in a context where their bodies, and the physical spaces it occupied and moved through were continuously monitored by their families through strict curfews.

People, especially girls, are not allowed to simply move around. Even at my house this happens, so I can't imagine what it may be elsewhere. If it's around 7 o'clock [in the evening] and I need something from outside then Papa says, "Just get it tomorrow morning". At these times I have to send my younger brother [to get what I wanted]. Thus while having the phone meant a continuous exchange across private and public time, no amount of phone time could bypass the clock time of the curfew imposed on women's bodies and spaces by families. The phone thus offered public time (ie chatting safely on WhatsApp from home) where public space was no longer possible to access, or provided private time when public space itself felt threatening. 


\section{Living with imminent violence}

A major part of women's daily lives went in anticipating danger. Women commented that they were neither safe inside nor outside the house. Stories of rape, incest and sexual harassment were common. Indeed each of the women interviewed had experienced sexual harassment in some form and they knew of someone in their family or neighbourhood who had been sexually assaulted. Hence, living with imminent danger was a reality and everyday aspect of their lives.

we were returning after marking the $8^{\text {th }}$ march events, for women's day, we were on the metro, this man kept staring at me for a long time, and my friend said, Didi, see how this man is looking at us- it feels like he is raping us with his eyes. Then I realized that he had taken our picture, and I asked him, "hey, you took a picture right”, he said, "no I didn't take any”, I said, “well, show me your phone” and I snatched his phone, asked him to open his phone and when he opened it, there were 67 photos. Then we caught hold of him and beat him up in the metro.

This vigilante 'justice' of physical and collective violence against men who were perpetrators of sexual harassment was frequently used by the women to keep themselves safe in the absence of regular channels of justice. The time of procedural justice was often described as 'slow', not least because many of them had experienced the police station as a threatening space, but also because complaints to the police or to the women's helpline were unfruitful. Each complaint required multiple follow-up calls to the helpline or personal visits to the police station, which was time-consuming when they were already struggling with time constraints.

but nothing really happened to that complaint, because we didn't have so much time to pursue it amidst our office work, we went to the police station once or twice when they had called us, that time our event was happening, so we didn't have time, we still 
tried, and we were 3 friends, and one wasn't ready to go, that I can't do this running around along with office work.

Managing their time therefore to avoid this danger at all costs was one of their primary strategies of staying safe in the city and in the neighbourhood. This strategy was adopted differently by the women, and by their families. For the former, living with imminent danger meant a continuous strategizing about when to go out, where to go and at which times of the day. For their families, danger was 'avoided' by installing further controls over women's times, spaces and bodies. All the women in the study faced strict curfew hours, and any violation of these hours would mean violence from within their own families. Indeed, a violation of the curfew hours was seen as a transgression into 'immorality' - dangerous and illicit relations with men who were not approved by the family.

if you take an average girl who is going at 9 in the morning and returning at $6 \ldots . .$. if she is delayed and it is 6:30 instead of 6, many times they are beaten up by their parents. “where were there for half an hour! who were you roaming around with!?”, and would give really degrading verbal abuses. You are the parents! You have to consider the difference between the environment at your time and how it is now.

The women were clear that the curfew as a way of coping with imminent danger revealed the faultlines of generational time - its asynchronicity between them as 'digital millenials' and the older generation who had grown up without mobile technologies and could not understand their importance for women's mobility. Instead they highlighted the contradictions between generational time and the time of imminent danger, because the curfew did not necessarily keep them safe from online abuse and sexual harassment. It was only in learning how to use the mobile phone safely that they could keep themselves safe when they went outside the home. It is through this realisation that the women argued for what could be suggested as a right to urban technology. 
$\mathrm{R}$ : if a girl is alone, if she has a weapon - she has a phone, in the last instance also, she can call someone, with 100 or some urgent call- if she's gone out, alone, that place is crowded, there is no bus, she is getting tensed, it is night, on the one hand she is tensed, and the other, she has to reach home- how will she and she is waiting for the bus, it is crowded, she's not able to board it - you can call home and inform them and ask someone to come, urgent, please come pick me.

The mobile phone itself was the reason why safety apps were not popular amongst these women. The safety apps did not work - they were slow because of their download speeds, because the phones used by these women did not have the capacity to download heavy apps and more crucially because the police was seen as the purveyor of slow justice if at all. The safety apps also aggregate the time of danger - a crucial element of violence, and therefore are not useful to understand and predict women's vulnerability in particular spaces. The women instead preferred the instantaneity and direct connectivity of the mobile phones to their family and friends rather than through the interface of the apps which were slow, insecure and were reliant on internet connections which were not always available.

The digital therefore was 'seen both as a habit and a habitus — something that we use, but also a space that we inhabit or occupy.'(Shah 2015, 11) The phone was a technology to occupy safe space and curate the co-presence of violence. Because violence against women was often connected to victim shaming, women used their phones to document how and when the violence occurred, as well as where it occurred.

And didi, whatever happens, now I make video, take photos, in case one needs to place evidence, when people don't believe you, I just click these days.

The production of different agencies mobilised to deal with the uncertainties of time struggles was a form of slow violence in their lives. Thrown in the peripheries with little resources and rights, their attributional violence remains unspoken and invisible within the 
'spectacular' nature of VAW in the city that can be mapped with apps or cctv surveillance in the smart safe city. The everyday mundaneness of their time struggles are not recognisable within safecity policies, which would have been directed towards them if there had been another tragic Nirbhaya case. Yet in the everyday mundaneness of time struggles, their displacement in the peripheries was 'temporal, geographical, rhetorical, and technological displacements that simplify violence and underestimate, in advance and in retrospect, the human costs' (Nixon 2011, 7). In other words, theirs was a slow violence wrought through a combination of history and geography and the 'landscapes of temporal overspill' (Nixon $2011,8)$ into the peripheries.

\section{Smart safe city from the margins}

The geographic asynchronicity between the 'incident' of violence in the smart safe city and the rhythms of slow violence in women's daily lives is produced from very different technologies of time - smart safety apps vs. urban infrastructure. On the one hand, the technologies of time related to smart safe city focus on an instantaneous time of violence by seeking to reduce download speeds, eliminate crashes and bugs and increase the speed of intervention; on the other hand, technologies of time related to use and access to urban infrastructures such as public toilets, transport, public spaces seek to reduce travel times, increase physical and digital connectivity and make work-life more efficient. It reveals how time is social, cultural and gendered in the everyday experiences of violence, which is neglected in the technologies of measuring, visualising and intervening in VAW through smart city technologies. Thus digital infrastructure itself becomes a form of slow violence that while drawing women as data entry points in safety apps simultaneously excludes them from a wider sense of belonging and right to the city.

Yet, despite claims to speed, efficiency and rationality, the smart safe city is marked by the disjunctures/flows between clock time and social time, between incident response time 
and spatio-temporalities of violence, between a technocratic 'fix' and everyday uses of technology. This temporality of violence exists not in opposition, but in parallel with the cartographic representation of violence in the smart safe city. This notion of time as speed imposed by the smart safe city is central to the transformation of marginal lives in the urban peripheries. For the urban poor, contrary to the promise of an accelerated urban modernity, the smart safe city creates new struggles with time. It transforms their historical and subjective relationships with mobility, transport, urban public services, family norms, as well as sexual and physical assault. Speed becomes the defining feature of urban marginality, transforming gendered social time and creating new temporal geographies of exclusion and marginality.

Table 1: Violence seen from the top down Smart Safe City vs. life in the margins

To conclude, the table above summarises and represents the notion of time across the top down vision of a smart safe city and the unfolding slow violence of life in the peripheries. Unlike the timeframe of the safety apps which focus on the multiple geolocated instantaneities of violence, for women living on the urban peripheries and struggling on a daily basis to access public transport, this unfolds daily, over a lifetime and is often generational - passed down as family norms. The pattern of violence experienced in the city is represented in the safety apps through aggregation across time, whereas for the women, this violence is periodical, sporadic, routine and cyclical between day and night. It is measured through a consciousness of the social and gendered nature of time, whereas in a safety app this is measured through the rationality of clock time. A major part of how women process this violence and understand it as part of their lives relies upon their relationship to past violence and future safety. Often women reflect upon this to either internalise and normalise the violence, but also this violence is a way to come to terms with their present 
condition. Future action then is a resolve to build capacity and knowledge to deal with violence more effectively, whereas in safety apps the future is a projection of past incidents of violence that are coded in algorithms of efficient response. Significantly, the aspirations of speed, both in the case of apps and life in the margins are unachievable - apps crash, they have slow download rates and do not work at all without a mobile network. For women, speed is stalled in the poor response of police incident rooms, slow justice from the judiciary and restrictive family norms which control their bodies and spaces. Finally smart phones are the ubiquitous technology of 'measuring' violence in the smart safe city whereas for the women this technology present in the absent, broken or disconnected infrastructures between home and the city.

Thus it is that speed, an apriori condition of urbanization, has become an authoritative force and a driver of new forms of violence. Time is the space of struggles, where its restraints, constraints and slowness determine women's struggles to claims their space in the city. The past is remembered to highlight injustices, whereas the present is claimed as a right so that the future may be secure. Young millennials on the margins ask how a radical rethinking in the notions of speed can shift the balance of power between time and space in the future city. In so doing they raise broader questions about the sites, scales and actors for reclaiming the future, and how this can be mainstreamed in urban policy, governance and everyday life.

\section{Acknowledgements}

This paper has been made possible through an AHRC funded research network (PI ref: AH/R003866/1 from 2018-2020). This project would not have been possible without the participation and enthusiasm of the young women in the low-income settlements in Delhi who were part of this research. I am grateful to Arya Thomas, our local research assistant for her hard work conducting interviews, WhatsApp methods and support in the community 
workshops. I am also grateful to Jagori and Safetipin for partnering on this project, and providing support and access to the community, recruiting participants, organising the workshops and feedback on this research. Parts of this paper were delivered as keynotes and I am grateful to the audience for raising questions that have helped sharpen the paper.

\section{References}

Adam, Barbara. 1995. Timewatch: The Social Analysis of Time. Cambridge UK: Polity Press. - 2004. Time. London: Polity Press.

- 2008. "Future Matters. Futures Known, Created and Minded', 21st Century Society." Journal of the Academy of Social Sciences 3 (2): 109-224.

Adur, Shweta M., and Shreyasi Jha. 2018. "(Re)Centering Street Harassment - an Appraisal of Safe Cities Global Initiative in Delhi, India.” Journal of Gender Studies 27 (1): 114-24. https://doi.org/10.1080/09589236.2016.1264296.

Amin, Ash. 2013. "Surviving the Turbulent Future." Environment and Planning D: Society and Space 31 (1): 140-56.

Anderson, Ben. 2010. "Preemption, Precaution, Preparedness: Anticipatory Action and Future Geographies." Progress in Human Geography 34 (6): 777-798.

Appadurai, Arjun. 2013. The Future as Cultural Fact: Essays on the Global Condition. London: Verso.

Banerjee-Guha, Swapna. 2010. Accumulation by Dispossession: Transformative Cities in the New Global Order. SAGE Publications India.

Bear, Laura. 2016. “Time as Technique." Annual Review of Anthropology 45 (1): 487-502. https://doi.org/10.1146/annurev-anthro-102313-030159.

Bell, Wendell, and James A. Mau, eds. 1971. The Sociology of the Future: Theory, Cases and Annotated Bibliography. New York: Russell Sage Foundation.

Bhan, Gautam, and Kalyani Menon-Sen. 2008. Swept off the Map: Surviving Eviction and Resettlement in Delhi. New Delhi: Yoda Press.

Chakrabarty, Dipesh. 2000. Provincializing Europe: Postcolonial Thought and Historical Difference. Princeton, NJ: Princeton University Press.

Chant, Sylvia. 2013. 'Cities through a 'Gender Lens': A Golden 'Urban Age' for Women in the Global South?" Environment and Urbanization 25 (1): 9-29. https://doi.org/10.1177/0956247813477809.

Datta, Ayona. 2012. The Illegal City: Space, Law and Gender in a Delhi Squatter Settlement. Ashgate Publishing, Ltd.

. 2017. "Introduction: Fast Cities in an Urban Age." In Mega-Urbanization in the Global South: Fast Cities and New Urban Utopias of the Global South, edited by Abdul Shaban and Datta, Ayona, 1-27. London: Routledge. 2018. "The 'Digital Turn' in Postcolonial Urbanism: Smart Citizenship in the Making of India's 100 Smart Cities." Transactions of the IBG 43 (3): 405-19.

Elwood, Sarah, and Agnieszka Leszczynski. 2018. "Feminist Digital Geographies." Gender, Place \& Culture 25 (5): 629-44. https://doi.org/10.1080/0966369X.2018.1465396.

Govt of NCT of Delhi. 2014. "Dept. of Women \& Child Development:" 2014. http://www.wcddel.in/streesakti_4SafeCiti.html.

Graham, Stephen, and Simon Marvin. 2001. Splintering Urbanism: Networked Infrastructures, Technological Mobilities. London: Routledge. 
Gurumurthy, Anita, and Nandini Chami. 2014. "Digital Technologies and Gender Justice in India - An Analysis of Key Policy and Programming Concerns." IT for Change. http://www.itforchange.net/sites/default/files/IT\%20for\%20Change\%20$\% 20$ HLPC $\% 20$ Submission\%20-\%2016\%20April\%202014-1.pdf.

Gurumurthy, Anita, Nandini Chami, and Sanjana Thomas. 2016. "Unpacking Digital India: A Feminist Commentary on Policy Agendas in the Digital Moment." Journal of Information Policy 6: 371-402. https://doi.org/10.5325/jinfopoli.6.2016.0371.

Herzog, Lawrence. 1995. "Fast Urbanism and Slow Urbanism: Globalization and Public Space in Three Mexican Cities." In The End of Public Space in the Latin American City, edited by Gareth A. Jones and Peter M. Ward. Austin, TX: University of Texas. . 2014. Global Suburbs: Urban Sprawl from the Rio Grande to Rio de Janeiro. Routledge.

Indian Express. 2018. "Delhi Police's Himmat App for Women Safety Failed to Serve Purpose: Parliamentary Panel," March 11, 2018.

https:/economictimes.indiatimes.com/news/politics-and-nation/delhi-polices-himmatapp-for-women-safety-failed-to-serve-purpose-parliamentarypanel/articleshow/63254248.cms.

Jagori. n.d. "Crossing Barriers Breaking Divides: Making Delhi a Safer Place for Youth." Accessed July 25, 2018. http://www.jagori.org/wp-content/uploads/2010/02/youthand-safety-report-english.pdf.

Jeffrey, Craig. 2010. Timepass: Youth, Class, and the Politics of Waiting in India. Stanford, CA: Stanford University Press. http://www.sup.org/books/title/?id=17650.

Keller, Jessalynn, Kaitlynn Mendes, and Jessica Ringrose. 2018. "Speaking 'Unspeakable Things': Documenting Digital Feminist Responses to Rape Culture." Journal of Gender Studies 27 (1): 22-36.

Kitchin, Rob. 2019. "The Timescape of Smart Cities." Annals of the American Association of Geographers 109 (3). https://doi.org/10.1080/24694452.2018.1497475.

Leszczynski, Agnieska. 2016. "Speculative Futures: Cities, Data, and Governance beyond Smart Urbanism." Environment and Planning A 48 (9): 1691-1708.

Light, Jennifer. 1995. "The Digital Landscape: New Space for Women?" Gender, Place \& Culture 2 (2): 133-46. https://doi.org/10.1080/09663699550021982.

Milojevic', Ivana. 2008. “Timing Feminism, Feminising Time.” Futures 40: 329-345.

Nixon, Rob. 2011. Slow Violence and the Environmentalism of the Poor. Cambridge, MA: Harvard University Press.

Sardar, Ziauddin. 1993. "Colonizing the Future: The 'Other' Dimension of Futures Studies." Futures 25 (2): 179-87. https://doi.org/10.1016/0016-3287(93)90163-N.

Sarkar, Sreela. 2016. "Beyond the 'Digital Divide': The 'Computer Girls' of Seelampur." Feminist Media Studies 16 (6): 968-83. https://doi.org/10.1080/14680777.2016.1169207.

Shah, Nishant. 2015. "Networked Margins: Revisiting Inequality and Intersection." In Digitally Connected: Global Perspectives on Youth and Digital Media, edited by Sandra Cortesi and Urs Gasser, 9-11. https://papers.ssrn.com/sol3/papers.cfm?abstract_id=2585686.

Tacoli, Cecilia, and David Satterthwaite. 2013. "Gender and Urban Change." Environment and Urbanization 25 (1): 3-8. https://doi.org/10.1177/0956247813479086.

The Hindu. 2004. "Madanpur Khadar Residents to Get Power Connections," 2004. https://www.thehindu.com/2004/07/13/stories/2004071317280300.htm.

Thomas, Pradip Ninan. 2018. Digital India: Understanding Information, Communication and Social Change. New Delhi: SAGE Publications India. https://uk.sagepub.com/en$\mathrm{gb} /$ eur/digital-india/book239556. 
Tutton, Richard. 2017. "Wicked Futures: Meaning, Matter and the Sociology of the Future." Sociological Review 65 (3): 478- 492.

Virilio, Paul. 2006. Speed and Politics. Pasadena, CA: Semiotext(e).

\section{Author Biography}

Ayona Datta is Professor in Urban Futures in the Department of Geography, University College London. Her broad research interests are in smart cities, urban futures, gender and politics of urbanization in the global south. She is author of 'The Illegal City: Space, law and gender in a Delhi squatter settlement' (Ashgate 2012), co-editor of 'Translocal Geographies: Spaces, places, connections' (Ashgate 2011) and of 'Mega-Urbanization in the Global South: Fast Cities and New Urban Utopias' (Routledge 2017). Ayona is author of several peer reviewed journal articles, op-eds as well as producer/director of two films on Mumbai's urban transformations 'City bypassed' and 'City forgotten'. She is co-editor of two journals Urban Geography and Dialogues in Human Geography; and on the editorial boards of Antipode and EPD: Society and Space. 